\title{
Por uma Nova Ontologia da Defesa
}

\section{For a New Defense Ontology}

Rev. Bra. Est. Def. v. 2, nº 2, jul./dez. 2015, p. 15-20

ISSN 2358-3932

\section{SAMUEL ALVES SOARES}

Os estudos em Defesa no Brasil talvez não alcancem meio século, quem sabe um curto meio século. Há uma dimensão da Defesa que ainda está para ser construída e consubstanciada. Há temas de Defesa, e são nitidamente temas de Defesa, que possuem uma larga tradição no Brasil, como estudos sobre indústria e economia de Defesa, tecnologia de emprego militar, estudos estratégicos, sociologia da guerra, e relações civis-militares em suas vertentes na História e nas Ciências Sociais, questões estas tributárias em particular ao regime autoritário vigorante entre 1964 e 1984. Não se trata, pois, de uma ausência, mas de fragmentação, por um lado, e de uma clareza ontológica sobre a dimensão central da Defesa, uma dimensão não estabelecida com o vigor que se poderia acalentar. Essa dimensão, desde um amparo normativo, é que a Defesa deve estar configurada na perspectiva da externalização, ou de uma nova ontologia da Defesa, que a encare, antes de mais nada, como ações que são tomadas para fora da esfera nacional e que envolvem, por certo, os estudos estratégicos e a questão da guerra. Porque o tema Defesa, inexoravelmente, encobre possibilidades de se tomar ações estratégicas - sejam ofensivas, defensivas, dissuasórias, etc. - isto é, que impliquem o uso da força.

Este é um debate fundamental e que envolve o seu significado e compreensão. Neste sentido, é somente ao término do regime autoritário que se começa a esboçar efetivamente este tipo de perspectiva. Observe-se que o próprio termo Defesa não aparece nos documentos dos anos 1960, 1970 e 1980. Isso não significa tudo, mas é um indício importante a se considerar. O que se apresentava no país, em parte, das próprias Forças Armadas, era a elaboração de uma Doutrina de Segurança Nacional que internalizou o conflito, enquanto caracterizou o inimigo como sendo interno, na medida em que ele se diferenciava do ponto de vista ideológico de uma ordem social pregada e imposta pela força. Essa é uma questão sobejamente conhe-

Samuel Alves Soares - Doutor em Ciência Política (USP) e professor de Relações Internacionais (UNESP). E-mail: samuel.soares@ippri.unesp.br 
cida, mas é importante fazer essa demarcação para propor que se trate do tema com mais clareza e precisão. Ressalte-se que não se concentra neste período o emprego das Forças Armadas no âmbito interno, o que já se fazia presente no século XIX.

A referida questão sugere, de início, que se trate analiticamente dois pilares complementares, e, portanto, que se distinguem. Há uma questão militar que passou a constituir-se como um nó institucional central para o processo de redemocratização. Havia que se construir mecanismos que se interpusessem à autonomia militar e que fundassem novos formatos de convivência entre as instituições militares e o poder político civil. Aquelas recém-saídas do exercício direto do poder político, fortalecidas politicamente, e que haviam estabelecido os parâmetros de uma transição pelo alto; o segundo frágil, sem clareza de propósitos e padecente dos acontecimentos que levaram Sarney à presidência da República. Exposto este gigantesco desafio, que embutia o temor de retrocessos, estavam presentes as condições para que o outro pilar, agora político-estratégico, fosse considerado como um quase monopólio das Forças Armadas. Considerando-se o tema de forma bastante ampliada, as questões de Segurança Internacional e Defesa permaneciam como atributos praticamente exclusivos das instituições castrenses.

Durante uma década este segundo pilar ficou restrito à ambiência militar, embora não exista um monopólio de discussões sobre segurança internacional exclusivamente nas Forças Armadas. É necessário relativizar essa afirmação, mas não porque seja contestada completamente, e sim porque os parâmetros perderam ou mesmo nunca estiveram orientados por uma perspectiva oriunda do poder político legitimado para definir as linhas mestras mais gerais da grande estratégia.

O resultado é que os temas de Segurança Internacional e Defesa ficaram reféns da matriz autoritária da Escola Superior de Guerra, em cujo eixo central predominou a enviesada distorção de uma Guerra Fria alongada, cujo marco mantinha-se arraigado ao espectro do inimigo interno, em combinação com uma geopolítica mais clássica, voltada ao estabelecimento de uma estratégia de presença nacional, instando, por exemplo, à ocupação do "vazio amazônico", sem consideração às civilizações ali presentes há milênios. Decerto estes marcos não são excludentes e exclusivos. Pode-se voltar mais no tempo e encontrar Góes Monteiro tratando das dificuldades que se apresentavam ao Brasil nos anos 1930, do ponto de vista estratégico, de se defender de um inimigo que era visto ao sul. Ou seja, questões político-estratégicas não estão ausentes, mas estão muitas vezes isoladas e fragmentadas.

Se considerarmos a segurança como condições para o exercício das próprias capacidades se poderá notar que inúmeras vezes aqueles que são 
destinados a prover a segurança são muitas vezes aqueles que ampliam a condição da insegurança, revelando sempre mais a contradição do próprio oximoro da expressão segurança. A Defesa, por sua parte, pode ser considerada como um conjunto de medidas destinadas a enfrentar distintos riscos, potenciais ou efetivos, ou reduzir a vulnerabilidade frente a esses riscos, e embutindo a possibilidade de emprego da força. Neste ponto, afrontando o que foi estabelecido nos documentos normativos desta área no país, há uma questão fundamental a destacar: a Defesa contra ameaças exclusivamente externas, e não preferencialmente ou predominantemente externas. A inserção deste aposto, na Política de Defesa Nacional em sua versão de 2005, foi oportunidade perdida para definir parâmetros claros e distintivos entre a Defesa - externa - e a Segurança em sua vertente interna, quer em seus desdobramentos para a região de fronteiras, quer para o âmbito da Segurança Pública. O resultado é que esses termos acabam ressurgindo e sendo retomados porque vigora certa imagem fantasmagórica da perspectiva da Segurança Internacional revelando, mais uma vez, essa dificuldade da externalização das questões relativas à Defesa. E essa indistinção entre Defesa e Segurança no âmbito interno expõe, além disso, um outro aspecto: os marcos teóricos analíticos que são definidos alhures e que parecem indicar que Defesa não é atributo de "Estados fracos", tampouco de emergentes. A Defesa estaria restrita às potências, estas sim envolvidas em situações de constante luta pelo poder a que os demais não estão afeitos e, quando estão afeitos, reservam-se a eles apenas tarefas subsidiárias no sentido de reforçar os elementos de segurança internacional a serem providos pelas grandes potências.

Nesta linha, o que caberia à periferia do sistema? Ficaria reservado aos demais países dar conta das ameaças externas de cunho bem específico: as chamadas novas ameaças. E o Brasil se insere neste modelo, até porque tem sido obsequioso em atender crescentemente a este tipo de desígnio, que é estabelecido exteriormente. $\mathrm{O}$ resultado, que se pode acompanhar diuturnamente, é o emprego dos elementos máximos de força do Estado para ocupação de comunidades e como polícias de fronteira. Este movimento impede a externalização das ameaças e dos inimigos que demandem, aí sim, o emprego máximo da força do Estado. Não bastasse, a Defesa, do ponto de vista dos documentos normativos, reside em um espaço pouco claro e quiçá esquizofrênico. Por exemplo, anuncia-se, no âmbito regional - vejamos a criação da Unasul e do Conselho de Defesa Sul-americano -, o propósito de diferenciar Segurança e Defesa, ao apontar para domínios em que o emprego da força deveria ser diferenciado: o que é relativo à Defesa e o que é relativo à Segurança em seu âmbito interno e no limite das fronteiras domésticas. 
O Brasil tem sido abalizador desta proposta de diferenciação, que, todavia, não se traduz em normas de decisão e ação política. Ao revés, o emprego das Forças Armadas no âmbito interno tem sido a prática corriqueira e está a ponto de ser banalizada em formato usual de atuação na região de fronteiras, como policiamento em grandes eventos e como instrumento secular na Segurança Pública.

E há outros desdobramentos neste tema e que são de natureza epistemológica, que visam definir os eixos de produção do conhecimento sobre Defesa, enfim, o estabelecimento de parâmetros designadores do estatuto de cientificidade da área. E aparece outra vez na questão do encaminhamento como área de conhecimento no debate acadêmico-científico brasileiro. A consideração pouco lisonjeira é que a Defesa se encontra em um limbo. Ou seja, a Defesa ainda não encontrou a exaltação de uma visão beatífica, e não é contemplada como área de conhecimento pelo CNPq. E o Comitê de Defesa, já existente durante um breve período, nos meados dos anos 2000, foi extinto há alguns anos. A questão é, portanto: aonde está a Defesa?

Não se trata de um simples dilema. Como área do conhecimento ela está onde estão os pesquisadores, nos ambientes em que se produzem reflexões, debates e de onde surgem proposições para o campo. Em relação à produção científica, aparece nitidamente em obras qualificadas, em produtos tecnológicos. Todavia, o estatuto, o patamar de valoração efetiva deste campo está por vir. Ou quando ele se anuncia, bem pouco tempo, na sequência, ele se retrai. E não há dúvida que há uma questão-chave: quando aqueles que se dedicam aos temas de Defesa têm a preocupação de, quando encaminham projetos, possam contar, pelo menos, com a consideração e o respeito de que as suas propostas e formulações possam ser avaliadas por pares da área, o que é uma condição absolutamente essencial para a aplicação do rigor acadêmico, mas com parâmetros orientados por uma razoabilidade de corte acadêmico. Este é um aspecto fundamental e importante.

Outra questão é se isso significa considerar os temas de Defesa como apartados, como distantes de outras áreas do conhecimento, como uma área tão específica que não consiga produzir o debate com áreas afins. É preciso tomar um cuidado entre o extremo do isolamento e da desconsideração e a excessiva fragmentação, de modo a garantir uma perspectiva mais institucionalizada que viabilize a consolidação da Defesa como área do conhecimento científico, respeitando um legado histórico que demanda um fortalecimento constante. É chegado o momento que exige cuidado com a excessiva euforia, porque, com dez anos da Associação Brasileira de Estudos de Defesa, poder-se-ia, por inadvertência, considerar que foi atingido um patamar já satisfatório. Ainda há muito a se fazer. E a Universidade 
precisa manter, ou pelo menos recriar, a sua condição de exercer um papel de vanguarda. A Universidade não pode ficar a reboque. É na Universidade que se propõe a agenda e a pauta. Há que se distinguir com muita clareza que a reflexão criteriosa, distante de doutrinas, de engessamentos, é papel da Universidade em seu pluralismo metodológico, epistemológico e ontológico. E com o cuidado de evitar o frequente risco de entorpecimento produzido por mecanismos burocráticos, aparentemente derivados das próprias proposições e que geram regras que aprisionam e que empobrecem o debate acadêmico.

E para evitar o isolamento, evadir-se de constituição de uma área apartada das Ciências Humanas e também de uma excessiva fragmentação. No campo estão inseridos temas já clássicos: estudos estratégicos, relações civis-militares, história militar, teorias da paz e da guerra, questões de gênero nas Forças Armadas, entre tantos outros. Propõe-se, para um debate franco e aberto, que a Defesa, desde um ponto de vista ontológico, está ligada ao campo das relações internacionais, em caixa baixa, pois não se está referindo ao campo específico do conhecimento, mas à externalização da Defesa no âmbito das relações internacionais. Este é o domínio ontológico da Defesa por excelência.

É preciso indagar-se acerca da concretude dos passos estabelecidos na esfera acadêmica e na dimensão da política. O fortalecimento acadêmico é tarefa essencial, embora não exclusiva, para conceder atributos fundamentais para a democracia e para o estatuto estratégico do país e da região. De um lado, o exercício constante para que se produzam as condições para o emprego da força máxima do Estado exclusivamente para ameaças externas, protegendo a cidadania de se tornar vítima dos elementos de força de seu próprio Estado. De outro, para que se evite uma resignação estratégica, que circunde a atuação das Forças Armadas a um papel subsidiário de polícias de fronteira, restritas a compor um aparato dedicado a conter fluxos de drogas ilícitas ou que se constituam, por fim, ao estatuto de polícias destinadas, muito equivocadamente, à Segurança Pública. Observe-se que este processo tem se apressurado, em dupla afronta: à democracia e à dimensão estratégica do país. Com ousadia e ambição é preciso conter este processo e ultrapassar a condição deste duplo debilitamento. É preciso estabelecer que a Defesa não está contida nos limites de fronteiras, físicas ou epistêmicas. 


\section{NOTAS}

1. Agradeço a Tiago Gabriel Tasca pela transcrição da exposição realizada durante o Encontro Regional da ABED - Sudeste, em novembro de 2015.

\section{POR UMA NOVA ONTOLOGIA DA DEFESA}

\section{RESUMO}

Ensaio acerca de como se desenvolveram os Estudos de Defesa no Brasil e como, no momento atual, é preciso que a área encontre o seu lugar na produção acadêmica brasileira. É preciso tomar um cuidado entre o extremo do isolamento e da desconsideração e a excessiva fragmentação, de modo a garantir uma perspectiva mais institucionalizada que viabilize a consolidação da Defesa como área do conhecimento científico, respeitando um legado histórico que demanda um fortalecimento constante.

Palavras-chave: Estudos de Defesa; Ontologia; Conhecimento Científico.

\section{ABSTRACT}

Essay on how the development of the Defense Studies in Brazil and how, at the present time, it is necessary that the area finds its place in the Brazilian academic production. One has to take a care not to place the Defense Studies at the extreme isolation and not to avoid its excessive fragmentation, in order to ensure a more institutionalized approach that enables the consolidation of Defense Studies as an area of scientific knowledge, following a historical legacy that demands constant strengthening.

Key-words: Defense Studies; Ontology; Scientific Knowledge. 